\title{
INCLUSÃO E APRENDIZAGEM: O DESAFIO DA ESCOLA ${ }^{I}$
}

\author{
Jaldete da Conceição Santana Santos ${ }^{2}$
}

RESUMO: Esse artigo é resultado da experiência profissional da autora dialogada a uma pesquisa bibliográfica que focaliza a análise de novas perspectivas de aprendizagem de pessoas com deficiência no contexto da inclusão escolar. A inclusão tem sido duran-te década, uma proposta desafiadora a ser vivenciada pelas escolas do ensino regu- lar. A prática escolar mostra que ainda não se conseguiu enfrentar tal desafio; po- rém, isso será possível somente quando acontecer na prática transformações signifi-cativas, tais desafios devem ser enfrentados, no século XXI com novas metodologiasde atendimento à diversidade. É objetivo desse desafio, propor a aprendizagem sig- nificativa como resultado da inclusão da pessoa com deficiência na escola comum. Éparadigma da diferença, o respeito à cidadania de todos os seres humanos conside- rando o processo histórico, as mudanças culturais, a superação de mitos, medos e tabus. Portanto, ainda se nota um abismo entre o texto escrito e a realidade vivida.

Palavras-chave: Inclusão. Deficiência. Desafio e Aprendizagem.

ABSTRACT: This article is the result of professional experience of the author to a dialogic per-quisa literature that focuses on the analysis of new opportunities for people with learning disabilities in the context of school inclusion. The inclusion has been for decades, a challenging proposition to be experienced by mainstream schools. The practice shows that school has not yet managed to address this challenge, but it will be possible only when significant changes occur in practice, such challenges should be addressed in the new century, new methods of service to diversity. It is the aim of this challenge, propose meaningful learning as a result of inclusion of persons with disabilities in regular schools. It is a paradigm of difference, respect for the citizenshipof all humans considering the historical process, cultural change, overcoming myths fears and taboos. Therefore, you can still see a gap between the written text and thelived reality.

Keywords: Inclusion. Disabilities. and Learning Challenge.

\footnotetext{
${ }^{I}$ Trabalho apresentado como pré-requisito para a conclusão do curso de Especialização em Educa- ção para a Diversidade e Cidadania, da Universidade Federal de Goiás - UFG, orientado pela Prof ${ }^{a}$. Esp. Vilma Ribeiro de Almeida e pelo Formador Prof. Dr. João da Cruz Gonçalves Neto.

${ }_{2}^{2}$ Pedagoga pela Universidade Estadual de Goiás - UEG - São Miguel do Araguaia, Especialista em Psicopedagogia Institucional pela UEG, Professora do Programa de Educação Inclusiva da Rede Estadual de Educação desde 1993.
} 


\section{INTRODUÇÃO}

Este artigo tem como finalidade tecer considerações bibliográficas a respeito da inclusão escolar da pessoa com deficiência para subsidiar a todas as pessoas, professores, pais, alunos e sociedade, que desejam entender a inclusão como pro- posta transformadora, onde a aprendizagem acontece mutuamente. A política edu-cacional para uma escola inclusiva deve desenvolver-se a partir do entendimento de todos e todas dos direitos humanos e do conceito de cidadania, fundamentado no reconhecimento das diferenças e na participação dos sujeitos, pois fatos históricosda educação das pessoas com deficiências vêm, ao longo da história, evidenciando diferentes compreensões, terminologias e modalidades.

Muitas ações inclusivas com a pessoa com deficiência estão apenas nos dis- cursos ideológicos de inclusão. Hoje, se faz necessário compreender que, no contex-to inclusivo é a escola que se modifica para oferecer um ensino de qualidade e a-tender a todos e a todas, independente das suas diferenças e necessidades especí-ficas que apresentam, objetivando o desafio de trabalhar com a diversidade e cons- truir um novo conceito de aprendizagem educacional.

Assim, através de uma abordagem bibliográfica, pesquisa, experiência profis- sional e observação in loco, pretende-se elencar pontos importantes a serem consi- derados no atendimento de necessidades educacionais, incorporações de princípios já provados dentro de uma pedagogia que tem o aprendiz e sua especificidade comocentro do ensino; enfim, com uma proposta de respeito à diversidade humana pre- sente no espaço escolar, respondendo aos estilos de aprendizagens, é que aconte- ce o sucesso de uma educação inclusiva da pessoa com deficiência no ambiente escolar

A pesquisadora prioriza essa linha de pesquisa em função de estudos anterio-res e de suas experiências vividas como professora, que somam i8 (dezoito) anosde trabalho com o ensino especial. Toma como base a Constituição Brasileira de 1988, que fundamenta a promoção do bem estar de todas as pessoas, sem precon-ceitos de origem, raça, sexo, cor, idade e quaisquer outras formas de discriminação,assim como o artigo 205, que define a educação como um direito de todos os sereshumanos e garantia do pleno desenvolvimento da pessoa, e correlaciona no artigozo6 os princípios para o ensino, de igualdade de 
condições de acesso e permanên-cia na escola para todos.

\title{
INCLUSÃO DA PESSOA COM DEFICIÊNCIA: UM DESAFIO DA ESCOLA
}

O conceito de inclusão é muito mais amplo do que o de integração ${ }^{3}$, porqueao incluir a escola se coloca no papel inovador para atender a todos e a todas, na totalidade. Assim, como aborda BLATYTA e RUBIINSTEIN (2005, p. 190) o ato de incluir "oferece ao educador um novo paradigma para compreender a queixa escolar, erros e falhas na aprendizagem". As necessidades educacionais incorporam os princípios já provados de que é necessária uma pedagogia centrada no aluno, pois, assim, essa beneficia a todos e a todas. Nesse contexto, a educação inclusiva assu- me uma importância maior no aspecto de renovação e busca incessante da demo- cracia, que só será alcançada gerando a todas as pessoas, incluídas ou não, o a- cesso à informação, ao conhecimento, aos meios de formação e ao exercício pleno de sua cidadania.

\begin{abstract}
A afirmação de que a inclusão representa à única e melhor solução para a- lunos, professores, pais e sociedade, põe em evidência o mecanismo dis- cursivo que opera para assegurar a eficácia do discurso. Sua fraqueza, en- tretanto, reside no fato de que em certo momento o discurso contradiz a rea-lidade educacional brasileira, caracterizada por classes superlotadas, insta- lações físicas insuficientes, quadros docentes cuja formação deixa a dese- jar. Essas condições de existência de nosso sistema educacional levam a questionar a própria ${ }^{3}$ ideia de inclusão como política que, simplesmente, in-
\end{abstract}

Frente a essa contribuição, deve-se rever os conceitos atribuídos ao verbo "incluir". Quando se faz inclusão na escola da pessoa com deficiência não se deve ficar preso em frases prontas como "todos somos iguais" para justificar a incompe- tência diante da análise dos resultados, onde o aluno passa vários anos na mesma série, fazendo as mesmas atividades de coordenação, pintura e colagem, sem pro- posta significativa e desafiadora.

Segundo ROSS (1979), a aprendizagem pode acontecer em decorrência de vários fatores, que fazem as pessoas se interessarem, assimilarem ideias, conheci- mentos e transformá-los em atitudes ou ações. Compreende-se assim que a apren- dizagem se dá no sujeito de forma e situações que possibilitam o desenvolvimento integral do ser. Acredita-se que a aprendizagem é possível para todos os alunos, considerando suas possibilidades, pois os limites do ser humano não oferecem pa- râmetros para medir o quanto se é capaz de

\footnotetext{
${ }^{3}$ Integração Trata-se da ação e efeito de integrar ou integrar-se (constituir um todo, completar um todo com as partes que faltavam ou fazer com que alguém ou algo passe a pertencer a um todo).
} 
aprender. A escola deve oferecer para todos os alunos condições e qualidade na forma de ensinar, permitindo que todos recebam subsídios que os levem a trilhar o caminho da aprendizagem de forma efi- caz, finalizando em sucesso educacional, social e, logo, na vida.

Formalmente, a escola trataria a todos de modo igual, todos assistiriam às mesmas aulas, seriam submetidos às mesmas formas de avaliação, obede- ceriam às mesmas regras e, portanto, supostamente, teriam as mesmas chances. (NOGUEIRA, 2002, p.87)

Segundo o autor, a escola com suas teorias ainda apresenta uma cultura es-colar no caminho de um currículo que é camufladamente dominante. Assim, afirma- se que a democratização do acesso à frequência escolar dada ao deficiente não as- segura a aprendizagem necessária, pois sua limitação intelectual dificulta a concretização da aprendizagem idealizada pela escola. Nesse processo, veem-se professores ainda privilegiando as aprendizagens mecânicas quando tem em suas salas de aulas deficientes intelectuais, ao contrário de propor situações desafiadoras baseadas em experiências vividas pelo aluno que torna o resultado em aprendizagem significativa.

Para OLIVEIRA (1997, p. 56) “[...] é o aprendizado que possibilita o despertar dos processos internos de desenvolvimento, que não fosse o contato do indivíduo com certo ambiente cultural, não ocorreriam”. Assim é definido o papel da escola com "todos", inclusive em relação à pessoa com deficiência intelectual inserida no ambiente escolar.

Segundo SASSAKI (1997, p.124-125) o programa da ONU em Deficiências Severas no ano de 1994 aponta que todos os estudantes, deficientes ou não, são beneficiados em vários aspectos dentro da escola inclusiva, como, por exemplo, adquirir experiência direta com a variação natural das capacidades humanas, apresentando crescente responsabilidade e melhora da aprendizagem através do ensino entre os alunos, melhora na preparação para a vida em uma sociedade com diferenças, desenvolvendo em escala crescente o conforto, a confiança e a compreensãoda diversidade individual deles e do outro, com responsabilidade e aprendizagem significativa.

$\mathrm{O}$ ato de educar é político, supõe intenções sobre o que se faz e acredita. Aceitar este desafio torna a escola e a sociedade capazes de acolher a todos e to-das independente de suas condições físicas, intelectuais, sociais, emocionais, linguísticas e outras, garantindo o exercício da cidadania por meios eficazes de comba-te à exclusão de pessoas com deficiências, do sistema educacional e social. Apesar de todas as polêmicas relacionadas à 
inclusão da pessoa com deficiência intelectual, a inclusão é o paradigma precursor de uma educação de qualidade, sem excluir nenhuma pessoa, atendendo a diversidade humana presente no espaço escolar e social.

Distância entre o nível de desenvolvimento real que se costuma determinar através da solução independente de problemas e o nível de desenvolvimento potencial de terminado através da solução de problemas sob a orientaçãode um adulto ou em colaboração com companheiros mais capazes. (VY-GOTSKY, 1996, p.97)

Para VYGOTSKY, os fundamentos teóricos da educação inclusiva que o indivíduo com limitações no processo da aprendizagem desenvolve está na ZDP (zona do desenvolvimento proximal), funções que estão no processo de amadurecimento para se consolidarem no nível de desenvolvimento real. Nessa formulação com a mediação do professor e a capacidade do olhar no aprendizado que está ocorrendo com o aluno, define-se o sucesso escolar do deficiente e também daqueles que fa- zem parte da diversidade no ambiente educacional.

\footnotetext{
A condição primeira para que a inclusão deixe de ser uma ameaça ao que hoje a escola defende e adota habitualmente como prática pedagógica é abandonar tudo o que a leva a tolerar as pessoas com deficiência, nas tur-mas comuns, por meio de arranjos criados para manter as aparências de "bem-intencionada", sempre atribuindo a esses alunos o fracasso, a incapa- cidade de acompanhar o ensino comum. (MANTOAN, 2009, p.39)
}

Para a autora, é preciso reverter essa postura de superioridade escolar quan- do se refere às pessoas com deficiência, e que os arranjos e adaptações feitas para manter-se diante de um comportamento de tolerância àqueles que "não aprendem" e que a lei lhes garante estar no meio dos outros para interagir, é "hipócrita".

Faz-se proponente à escola, reconstruir seus conceitos de aprendizagens considerando as contribuições produzidas através das diferenças em sala de aula. Simplesmente adaptar atividades a alguns alunos não condiz com os objetivos de uma educação inclusiva. Uma vez que essa acontece, considera-se o processo e a forma que apresentam o aprendizado como resultados positivos daqueles que têm deficiência. $O$ discurso é sempre que o deficiente, principalmente o deficiente intelec-tual, ainda "não conseguiu fazer igual à turma”, "ele não acompanha”. O ensino pre- cisa se projetar a partir daquilo que o ser humano tem como possibilidades, as adap-tações deverão atender a essas "possibilidades" sendo um modelador externo da aprendizagem do deficiente intelectual e de todos. 
Portanto, o desafio da inclusão da pessoa com deficiência na escola ultrapas- sa o ato de matriculá-lo em determinada série, é necessário oferecer métodos, ativi-dades e oportunidade de participação efetiva que tenham propostas de uma apren-dizagem significativa, que produzam conhecimento e, consequentemente, uma transformação no ser.

\section{INCLUSÃO ESCOLAR: NÃO BASTA ACOLHER, É PRECISO GARANTIR APRENDIZAGEM DE QUALIDADE A TODAS AS PESSOAS}

Por se tratar de uma pesquisa bibliográfica baseada nas experiências pesso- ais como educadora este artigo revela vários fatores ocorridos durante o estudo que apresentam um

érie de vantagens para o uso de documentos na pesquisa ou na avaliação educacional; ou seja, partindo da análise de vários referenciais bibliográfi- cos significativos e pertinentes ao tema proposto, tais como: leis, pareceres, decla- rações, bibliografias e experiências pessoais.

Esta é uma abordagem qualitativa, onde "pesquisador qualitativo fica imerso no fenômeno de interesse" (FIRESTONE, 1987, p. I6-17) tomando o ambiente e experiências vividas como instrumento de investigação, que descritivamente será desenvolvida em aspectos bibliográficos, considerando as contribuições que os do- cumentos e teóricos possuem, pois é através da legitimação destes, que novas prá- ticas, podem ser transformada. Embora esteja inteiramente voltado para educação o estudo teve a finalidade de mostrar a importância da análise bibliográfica nas áreas social, familiar e principalmente, educacional.

Estar na escola somente não é garantia de inclusão. Nessa perspectiva é que se apresentam números elevados de situações de inclusão de pessoas com neces- sidades educacionais especiais; no entanto, sem o devido respaldo e compreensão que lhes assegura a aprendizagem através de métodos, currículos e técnicas edu-cacionais que atendam suas necessidades, como garante a LDB (Leis de Diretrizese Bases) no artigo 59.

Acessibilidade não é mais o "carro chefe" das políticas públicas da educação, mas sim a possibilidade de incluir para provocar no ambiente inclusivo, práticas que proponham mudanças de postura na sociedade. Hoje parece ser "luxo" dizer minha escola é inclusiva, mas, o questionamento é inevitável: Que tipo de ensino ofereçoao meu aluno com deficiência? Deficientes intelectuais aparecem numa proporçãode 3 a 5 anos de reprovação em uma mesma série, justificando que ele não aprende.Segundo VYGOTSKY (1989), a 
pessoa com algum tipo de deficiência não é menos desenvolvida que as demais, mas desenvolve-se de forma diferente. De acordo com o autor, o limite, seja ele físico sensorial ou mental, pode levar a um acúmulo de e-nergia psíquica que dependendo do apoio do meio social, resulta em desenvolvi- mento cognitivo diferenciado. Daí suas reais possibilidades de aprendizado, que se distinguem daquelas apresentadas por pessoas sem deficiência específica, eviden- ciando o ritmo e os caminhos percorridos na realização de suas funções mentais superiore

e modo geral, a universalização do acesso e da permanência de todos os alunos às escolas comuns não implica em receitas fantásticas ou em meras modifi- cações de ordem física e material, mas refere-se essencialmente a mudanças para-digmáticas que, por sua vez, refletem novas formas de pensar e novos comporta- mentos e atitudes. Assim, no interior dessas mudanças gerais, inclui-se ainda a ado-ção de alternativas educacionais, compondo uma organização pedagógica realmen- te voltada aos diversos níveis, estilos e ritmos de aprendizagem.

Por isso é que esse trabalho propõe a todos os professores, pais e sociedade uma reflexão

acerca de todo fazer pedagógico relacionado à pessoa com deficiên- cia, essencialmente com deficiência intelectual. É necessário que eles estejam numaperspectiva inovadora e atualizada para que a mudança pragmática aconteça, assimcomo no âmbito de formação docente, nas políticas educacionais e sociais, que con-siderem as possibilidades de todos como direitos cumpridos e respeitados.

\section{CONSIDERAÇÕES FINAIS}

A educação inclusiva pressupõe que haja significativas transformações administrativas e pedagógicas no âmbito da organização do sistema de ensino. Essa proposta evoluiu mais na política educacional do que na prática, foram promulgadas muitas leis desde os anos 6o até a atual LDB (Leis de Diretrizes e Bases), mas evi- dencia que os objetivos, as metodologias e a aplicabilidade não foram colocados na prática, de forma a promover uma aprendizagem significativa e de qualidade.

A inclusão escolar garante à escola o desafio de trabalhar com a diversidadee construir um novo conceito do processo ensino aprendizagem, eliminando definiti-vamente o seu caráter segregacionista, de modo que sejam incluídas todas as pes- soas pelo simples 
direito de serem sujeitos sociais.

A efetiva inclusão depende de um trabalho contínuo da escola, pais, alunos, professores, especialistas e a sociedade como um todo. Cabe à escola e, principal-mente ao professor (a), a habilidade de trabalhar com classes heterogêneas, utili- zando conteúdo egundo SASSAKI (1997), para incluir todas as pessoas, inclusive aquelas que têm deficiência, deve-se aprender a conviver e se adaptar às diferenças, ser capaz de atender as necessidades de todas as pessoas partindo de princípios como valorização, aceitação e convivência com a diversidade, dando oportunidade con-forme as possibilidades da pessoa com deficiência. Assim, é possível valorizar a consciência cidadã, humanitária e também o cumprimento da legislação.

Atender a diversidade no ambiente escolar, respeitando os estilos de aprendizagem, afirma um compromisso de incluir, oportunizando o ato de aprender, com qualidade.

\section{REFERÊNCIAS}

BLATYTA, Dora Fraygman; RUBINTEIN, Edith. Psicopedagogia e Transdisciplinaridade. In FRIAÇA, Amâncio [ET AL]. Educação e transdisciplinaridade III. SãoPaulo: Triom, 2005.

BRASILEIRA, Constituição de 1988.

CAPELliNi, Vera Lúcia Messias Fialho (org.). Formação de professores na perspectiva de educação inclusiva Vol. 3,4 e 5 Bauru: UNESP/FC/MEC, 2010.

CARVALHO, Lorena Rezende, (org.). Atendimento Educacional Especializado- AEE: perspectivas para educação inclusiva em Goiás, Caderno 2, Goiás-See/CEE, 2010.

FIRESTONE, W.A. Significado em método: a retórica da pesquisa quantitativa e qualitativa. Educational Researcher: 16-21, 1987.

GÓES, M.C.R.; LAPLANE, A.L.F. Políticas e práticas de educação inclusiva. Campinas: Autores Associados, 2004. INEP. Dados do IDEB 2009. Disponível em: <.http://www.inep.gov.br/imprensa/noticias/ideb/newsı_or.htm> Acesso em: I8 agosto de 20II.

MANTOAN, M.T.E. Inclusão escolar: pontos e contrapontos. São Paulo: Sum- mus, 2006.

NOGUEIRA, C.M.M., Nogueira, M.A. A Sociologia da educação de Pierre Bourdi-eu: 
limites e contribuições. Educação e Sociedade. Campinas, v. 23, n.78, p.58- 78, 2002

OLIVEIRA, Martha Kohl. Vygostsky: Um aprendizado e desenvolvimento: um processo sócio-histórico. São Paulo: Scipione, 1997.

Revista Integração, Ser diferente é algo comum, Ano 5- № 13 - 1994

Revista Teias - Movimentos sociais processos de inclusão e educação. VI2 • n. $24 \cdot$ p. 39-55 • jan./abr. 2011

ROSS, Alan Otto. Aspectos Psicológicos dos Distúrbios da Aprendizagem e Dificuldades na Leitura. São Paulo: McGraw-Hill, 1979.

SASSAKY, Romeu Kasumi. Inclusão: construindo uma sociedade para todos.

Rio de Janeiro, WVA, 1997. VYGOTSKY, L. S. Pensamento e Linguagem. São Paulo: Martins Fontes, I989. 